\title{
The Importance of Role Sending in the Sensemaking of Change Agent Roles
}

\author{
Danielle A. Tucker* \\ London School of Economics and Political Science, UK \\ Jane Hendy \\ Healthcare Management and Policy, University of Surrey, Guildford, UK \\ James Barlow \\ Business School, Imperial College, London, UK
}

\section{Citing this article:}

This document represents an accepted draft of the final manuscript. The published version of this paper is currently in press and will be available at the following link: http://www.emeraldinsight.com/journal/jhom

\section{This paper should be cited as follows:}

Tucker, D. A.; Hendy, J. and Barlow, J. G. (in press) The importance of role sending in the sensemaking of change agent roles. Journal of Health, Organization and Management. 30(2):forthcoming 


\begin{abstract}
Purpose: In this paper we investigate what happens when a lack of role sending results in ambiguous change agent roles during a large scale organisational reconfiguration. We consider the role of sensemaking in resolving role ambiguity of middle manager change agents and the consequences of this for organisational restructuring
\end{abstract}

Design/methodology/approach: Data were collected from a case study analysis of significant organisational reconfiguration across a local National Health Service (NHS) Trust in the UK. Data consists of 82 interviews, complemented by analysis of over 100 documents and field notes from 51 hours of observations collected over five phases covering a three year period before, during and after the reconfiguration. An inductive qualitative analysis revealed the sensemaking processes by which ambiguity in role definition was resolved.

Findings: Our data explains how change agents collectively make sense of a role in their own way, drawing on their own experiences and views as well as cues from other organisational members. We also identified the organisational outcomes which resulted from this freedom in sensemaking. This study demonstrates that by leaving too much flexibility in the definition of the role, agents developed their own sensemaking which was subsequently very difficult to manipulate.

Practical implications: In creating new roles, management firstly needs to have a realistic vision of the task and roles that their agents will perform, and secondly, to communicate these expectations to both those responsible for recruiting these roles and to the agents themselves. 
Originality/value: Much of the focus in sensemaking research has been on the importance of change agent's sensemaking of the change but there has been little focus on how role expectations act as sensemaking cues for change agents

Keywords: Reconfiguration, change management, change agents, role ambiguity, role selling, sensemaking. 


\section{The Importance of Role Sending in the Sensemaking of Change Agent Roles}

Healthcare reconfiguration is challenging, and the use of champions or change agents has been widely accepted as best practice (Soo et al., 2009, MacFarlane et al., 2011, Chreim et al., 2012). Change agent sensemaking, in particular, has been found to be a key factor in the success of organisational reconfiguration (Hendy and Barlow, 2012, Balogun and Johnson, 2004, Parry, 2003). Sensemaking is the process by which new meaning is created to rationalise the actions of individuals in relation to change (Balogun and Johnson, 2004, Gioia and Chittipeddi, 1991, Maitlis and Sonenshein, 2010, Weick, 1995, Weick et al., 2005). Interpretive schemes are socially constructed from the connecting of cues and frames by organisational groups (Maitlis and Sonenshein, 2010). This process is influenced by existing knowledge (expectations and existing logics) as well as attempts to influence sensemaking from others (i.e. sensegiving) (Gioia and Chittipeddi, 1991, Humphreys et al., 2012). Much of the focus in research has been on the importance of change agent's sensemaking of the change (Gioia and Chittipeddi, 1991, Naslund, 2009, Tucker et al., 2012, Rouleau, 2005) but there has been little focus on the how sensemaking plays a role in the interpretation of the change agent role itself. This sensemaking is important because it will help us to understand how change agent roles should be created, designed or managed. The current lack of understanding about change agent roles is argued to be one of the determining factors in determining the extent to which agents are found to improve change management processes in healthcare organisations (Greenhalgh et al., 2005, Locock et al., 2001). Our research will inform healthcare managers responsible for the management, recruitment and evaluation of change related roles in how practice can be improved.

Role theory suggests that roles are created through the social process of role expectations provided by related others within the organisation (Katz and Kahn, 1978). For those with clinical backgrounds in managerial roles, contextual cues and agency motivations 
play a key role in determining role behaviours in addition to top-down role sending by senior managers (Mantere, 2008, Bolton, 2005). Change agents are important because they encourage readiness for change in others and facilitate change processes during implementation by problem solving and coordinating resources (Hanney et al., 2003, Chreim et al., 2012). In practice, the change agent role is especially complex. Often change agents are created and then left to their own devices (Hendy and Barlow, 2012, Soo et al., 2009). This has led to a neglect of understanding how managers (and change agents specifically) understand their own role in the transition (Hales, 1999).

Understanding the change agent role is especially important due to the complex nature of healthcare change, the political and multiple stakeholder views which are influential and issues of resources (Chreim et al., 2012, Dobers and Soderholm, 2009, Dobson et al., 2010, Eccles et al., 2005, MacFarlane et al., 2011, Ferlie et al., 2003, McNulty and Ferlie, 2002, Pettigrew et al., 1992). Moreover, there has been much focus on the success (or complications) of agents in healthcare change projects, often referring specifically to champions (as a particular enactment of change agency) by the organisation (Hendy and Barlow, 2012, Soo et al., 2009). Much of this research has demonstrated how unpredictable change agent success is (Greenhalgh et al., 2004, Locock et al., 2001). In this paper we argue that this is due to a lack of shared understanding about how the role should be enacted.

Here we investigate what happens when a lack of role sending results in ambiguous change agent roles during a large scale organisational reconfiguration. We consider the role of sensemaking in resolving role ambiguity of middle manager change agents and the consequences of this for organisational restructuring.

Change agent role complexity and role ambiguity in healthcare 
In healthcare research, the role of managers with a clinical background (e.g. nurse managers) has been highlighted as being very important for implementing cultural change (Bolton, 2005). It is suggested that giving nurses managerial roles will empower them as organisers of care and having involvement in managerial activities, such as allocation of resources, encourages initiative, self-reliance and self-development (du Gay, 1996). Managers with a clinical background act as transformational leaders and agents of change due to their ability to adopt a pragmatic style: interpreting and implementing management policies into an achievable programme within the strict confines of their immediate healthcare setting (Bolton, 2005).

The use of change agents in managing change is widely advocated, especially in healthcare. However many initiatives cite ineffective agents as a reason for failure (Greenhalgh et al., 2004, Balogun, 2010, Hendy and Barlow, 2012). A large part of the difficulty in synthesizing reasons for ineffectiveness of change agents is the many different interpretations on the role that agents should play. Research has focused on several types of agents in particular: Champions who actively and enthusiastically promote innovation and change to others and identify with the idea beyond normal job requirements (Howell and Higgins, 1990, Schon, 1963). Opinion leaders who are influential because they have an expert or respected view which guides others (Locock et al., 2001). Whilst other interpretations highlight the importance of encouraging readiness for change and facilitating change processes during implementation by problem solving and coordinating resources (Hanney et al., 2003, Chreim et al., 2012).With such significant differences in the characteristics, abilities and skills needed by each of these role profiles, a great deal of role interpretation is required to ensure that the individuals fulfilling these roles have an accurate understanding of their duties and responsibilities. 
Middle manager change agents may also take on more than one role at a time, adding to the complexity of role enactment. Bolton (2005) gives some insight into how agents juggle multiple roles. She demonstrates how nurse managers are able to maintain a distance from certain aspects of the role only embracing the aspects of strategy which aligned with their own interests. This is supported by the finding of Mantere's (2008) study of 262 middle managers which suggested that middle managers play a strategic agency role in determining their interpretation of role expectations. Together these studies emphasise that the change agent is not just a passive recipient of role expectations but that they play an active part in determining their own role behaviour.

Therefore understanding how change agent roles in healthcare organisations are created is especially important. Theories of sensemaking are useful to understand how organisational members create collective meaning during change efforts. In particular, Baker, Day and Salas (2006) found that sensemaking facilitated the development of a positive identification with work roles in healthcare. We therefore consider how sensemaking research may help us to understand the development of change agent roles.

\section{Sensemaking in organisational change}

Sensemaking is a process by which a mental model of events is developed which acts as an interpretive scheme for the actions and behaviour of individuals in explaining past behaviour and influencing subsequent situations (Gioia and Chittipeddi, 1991, Gioia et al., 1994, Maitlis, 2005, Maitlis and Sonenshein, 2010, Weick, 1995, Weick et al., 2005). This framework allows organisational members to comprehend events, attribute meaning and predict future events (Weick, 1995, Starbuck and Milliken, 1988). The basis of this framework consists of information which is gathered from the organisational context in many forms; conversations, documents, storytelling, behaviours and actions (Balogun and Johnson, 
2004). Sensemaking is a useful theoretical frame to advance our understanding of the creation of change agent roles because it seeks to unpack the process of interpreting stimuli from a cognitive perspective - for example, how change agents come to understand their role expectation and what may lead them to act in a particular way in a given situation (Balogun and Johnson, 2004, Rouleau, 2005, Weick et al., 2005, Evans and Baker, 2012). It takes into account the social nature and collective process which is present in the negotiation of new role expectations.

The importance of the sensemaking of change agents during change has often been highlighted (Gioia and Chittipeddi, 1991, Rouleau, 2005, Tucker et al., 2012). In particular it has been suggested that special attention needs to be paid to the sensemaking of middle managers as agents (Balogun, 2010, Balogun and Johnson, 2004, Birken et al., 2012, Rouleau, 2005). Middle managers are tasked with translating and implementing strategic organisational goals at an operational level (Ball et al., 2009, Currie and Procter, 2005, Mantere, 2008, Rouleau, 2005, Wooldridge et al., 2008). Whilst we know a considerable amount about the importance of change agent sensemaking about the change strategy itself, an area which has been relatively neglected in the literature is how sensemaking about the change agent's role itself can play a part in the change.

Important literature on role theory highlights the importance of role sending on influencing the enactment of roles. Roles are socially constructed by individuals who enact similar or related roles through a cyclical process of role sending and role expectations (Katz and Kahn, 1978, Currie and Procter, 2005). Similarly sensemaking is a process where the actions of individuals (i.e. their enactment of the role) generate environmental cues which act as raw material for sensemaking to occur (Maitlis and Sonenshein, 2010, Weick, 1988). Role expectations are a set of beliefs and attitudes about what the role in question should consist of. These are predominantly activity based expectations but may also be concerned with 
personal characteristics and expected beliefs and attitudes around how a role-holder conducts him/herself. These role expectations are communicated via a process of role-sending. They could take the form of instructions, formal role descriptions, and allocation of tasks or evaluations of current behaviour. Role sending may or may not be tangible and therefore may require the role-holder to interpret the communication to understand how they should adjust their behaviour (Katz and Kahn, 1978). The received role is based on the perceptions and cognitions by the role holder. How well aligned the received role is with the sent role will depend on the properties of the role holder, the role sender, the context of the expectations and clarity of the communication (Turner, 1978). Role behaviour may also be influenced by other organisational cues such as the actions of other organisational members (Currie and Procter, 2005). Organisational factors (e.g. reward systems, procedures), interpersonal factors (e.g. trust in the role sender) or attributes of the person (e.g. propensity of an individual to behave in a certain way) have all been found to have an impact on the creation of role behaviours (Katz and Kahn, 1978).

Role sending by related organisational members represents an attempt to guide the sensemaking of the role and to influence the role activities. Where a new role, to address a specific organisational need (i.e. the change project), is created it is likely that conflicting role expectations will attempt to pull the role enactment in multiple different directions to adjust the fit of the role to the gap which has been created. We might anticipate that this role sending process is very influential in creating the role behaviour which determines the enactment of the change agent role.

So, in implementing organisational change effectively, agents need to make sense of the change as well as the role which they are expected to play in managing the change. In this paper we ask, firstly, how does role sending influence the role behaviour of change agents? Secondly, what is the role of sensemaking in helping to resolve role ambiguity? And finally, 
how does this process determine successful organisational outcomes? To answer these questions we consider the sensemaking about a newly created change agent role in a case study of substantial organisational change.

\section{Methods}

\section{Study context and approach}

The case study involved a combination of physical infrastructure change, service redesign and a significant organisational reconfiguration across a local National Health Service (NHS) Trust in the UK. The infrastructure change involved the closure of two existing hospitals and a move to a new purpose built facility. The service redesign involved moving from old-style open-plan wards to an all single bedroom model. The increase in single rooms in hospitals has received significant political backing in the UK, with all new build hospitals now required to increase their single room provision. Single bedrooms challenge existing operational practices, for example through the decentralisation of nursing staff and reduced visibility of patients, but are also argued to improve recovery rates and reduce infection rates in hospitals (Snow, 2008). The complexity of combining work process and infrastructure change has been highlighted in recent research (Tucker et al, 2014).

At this organisation a parallel reconfiguration of local health services (closure of some services at one site) also resulted in considerable political, community and media attention for the Trust, including protest marches, petitions and the demands for a Government judicial review. The Trust was no stranger to political and media attention. In the previous 12 years it had experienced a merger with another Trust and a highly publicised infection scandal, resulting in the removal of the majority of board members. There was also concern about the cost of the long-term private finance contract for the construction and operation of the new 
hospital. Therefore ensuring a successful transition to the new hospital under so many watchful eyes was vital.

Rather than bringing in external consultants, the Trust decided to manage the transition internally, to make use of the knowledge and experience of its staff. A project management team was created, change management training for senior management established, and each of the hospital's four clinical divisions selected an individual change agent (who they referred to as project managers) to facilitate transition change management. These individuals were seconded into the role, filling a gap between the project team managing the construction and move, and clinical groups. These individuals all came from clinical backgrounds and had been working within the Trust for a number of years. Their previous roles varied, but they were generally viewed as individuals who had a good relationship with the organisation and were ready (and available) for a new challenge.

It became apparent in the early stages of data collection that this particular group of change agents were likely to be crucial in the stakeholder engagement and the overall change management strategy. In this paper we focus our attention on this group of change agents and specifically how they collectively made sense of the role. The move to the new hospital took place over two phases in 2011 - referred to here as 'transition 1' and 'transition 2'.

These agents were seconded into a two year position. This role formed the main link between the project team, managing the construction, move and migration into the new facility, and the clinical divisions providing care in the new hospital. They were formally appointed approximately 18 months prior to 'transition 1', remaining in post until immediately after completion of 'transition 2' (26 months in total). The creation of this role did not form part of the original change management plans of the organisation. The original intention was that divisional managers would work together with the project team to implement the change. However, as the opening of the new hospital approached in became 
apparent that a gap was forming between these two groups and therefore a decision was taken to create this new role.

The agents had strong relationships with divisional managers (each division was led by a team of three divisional managers, representing medical, nursing and management), but until secondment had not worked with their counterparts in other divisions. They did however quickly become a united group, combining their experience and interpretations of the role with each other. Their sensemaking of the role was likely to be influenced by these relationships and we therefore widened our range of participants to observe this. Other middle managers also became key informants throughout the project and we have used their accounts and their experience of the transformation to triangulate our interpretations and to evaluate the role.

\section{Data collection}

We have conducted 82 interviews, complemented by analysis of documentary evidence (over 100 documents have been analysed, including internal documents, publicly available reports and research, and media coverage) and field notes from observations (including new and old hospitals tours led by members of the Trust management and informal research observations and impressions). Two researchers spent significant amounts of time residing in the local area during these data collection periods and much of this time was spent at the hospital. Extensive notes and impressions were recorded during this period and these were consolidated into memos and field notes at the end of each period. Observation included informal conversations with members of staff and the local community, observation of interactions in public areas of the hospital and informal tours or visual explanation given by interview participants outside of the formal recorded interview. In addition, we were invited to attend several meetings and focus groups which were discussing the transition where we 
were able to take notes and collect documents to support our analysis. The data were collected over five phases covering three years (see table 1).

INSERT TABLE 1 HERE

Initially, interview participants were selected with the help of a lead contact within the organisation, key members of the executive team and individuals in roles specific to the new hospital build including the divisional project managers who are our focus of study. Additional participants were sampled based on the initial interviews, and included anyone identified as significant to the change management programme by other members. In phase 1 of data collection (approximately one year prior to 'transition 1') we focused on gathering accounts concerned with the historical context, and drivers and broad strategic aims of the change project. The recently appointed change agents were asked to consider these accounts in relation to the creation and purpose of their role, the sensemaking of their role and attitudes related to this.

Phase 2 (approximately three months prior to 'transition 1') emphasized accounts of the final planning stages and its challenges. The agents, now in post for 12-18 months, were able to reflect on the sensemaking of the role over the previous nine months. Phase $3 \mathrm{a}$ focused on employees directly involved in 'transition 1'; phase $3 b$ focused on those directly involved in 'transition 2', and representatives from the executive team and project office overseeing the work. Our attention was on evaluating the enactment and sensemaking of the role as well as overall evaluations of organisational outcomes. Agents were interviewed in the final weeks of the change, or shortly after the termination of their secondment, as they returned to their previous (or in some cases, new) roles. In the final phase we revisited some 
of our key informants approximately 12 months after 'transition 2' took place to gain a long term evaluation of the roles and their effectiveness.

\section{Data analysis}

Interviews were transcribed and analysed at different levels allowing for constant comparison between the data and the findings (Corbin and Strauss, 2008). Initially, an historical context for the case study was derived from documentary evidence and early interview analysis to understand how the creation and enactment of the roles orientated around significant events. At the first coding stage we were guided by our research questions in the identification of concepts relating to sensemaking, role descriptions, role sending, expectations and evaluations of the role, understanding of the drivers for change management and engagement, causes and implications of agent behaviours. We used an open coding approach to expose the ideas, thoughts, impressions and meanings of agent's understanding of their role. Next these open codes were compared for similarities and differences, to create conceptually similar groupings. Our observation field notes and document analysis was helpful in helping us to understand some of these differences, we were able to gleam much of our contextual understanding and interpret the use of specific language from these observations and interactions. We used these to create more distinct higher-order categories addressing the process of sensemaking. At each stage of the analysis, members of the research team met to discuss interpretations of the findings, compared analysis and discussed any inconsistencies. There was broad agreement in our interpretations throughout and any inconsistencies were addressed by referring back to the original transcripts.

\section{Findings}


We approached the data with our three research questions in mind. We firstly wanted to understand the creation of the role and how role sending influenced the role behaviour of change agents. The ambiguity which resulted from a lack of role sending enabled us to study in detail the sensemaking process at work. Below we explain how the change agents collectively made sense of the role in their own way, drawing on the known expectations of others and their own experiences and ideas. And finally, we identify the organisational outcomes which resulted from this freedom in sensemaking.

\section{Role creation and (lack of) expectations}

The addition of a change agent role for each division was not in the original plans of the organisation for implementing the new change for the hospital. However, approximately 18 months prior to transition 1 the managers became aware of a widening gap between the project team with the specific role of designing and building the new hospital and the clinical divisions which would be carrying out the care in the new facility. In an attempt to fill this void, each of the four clinical divisions were instructed to create a new role solely to facilitate transition planning at a divisional level:

"We needed some individuals to act as the glue between this scheme [the project office] and going right back into their division" (Member of the project team, phase 2)

The role was appointed by divisional leaders and no formal job description was produced. Our interviews at phase 1 were unable to draw a consensus on the role expectations held by senior managers or divisional managers. In truth, and as was reflected in hindsight by senior managers themselves, they had no specific expectations of the activities or behaviour which the change agents should exhibit: 
"Without a doubt; I think there is a real lesson in thinking about what we wanted from that role - there wasn't consensus about what was the priority of those individuals" (Senior manager, phase 3b)

"I don't think we really put enough effort into actually identifying exactly what was needed out of that role and what the expectations were" (Senior manager, phase 4).

All they knew was that there was gap, and they needed to fill that gap with a new role:

“They [senior managers] were saying, there's a gap here, right okay, we'll plug it with a role. We'll call them [official job title]. They didn't really know what they wanted, they just made it up afterwards like they'd pulled it out of a hat... they weren't really sure what the role would be at that time." (Change agent, phase 3b).

Some post-hoc explanations for this attempted to argue that the role was deliberately loose to allow flexibility and interpretation on the part of the change agents. Some suggested that the first task of the change agents should be to decide the purpose of the role for themselves which, as we will see later, turned out not to be a satisfactory direction:

"We gave them the opportunity to take it [the role] away and mould it into something which would be useful; we wanted them to have ownership of the position" (Senior manager, phase $3 a$ )

"Someone at that grade shouldn't need to have their hand held all the time, it was their job to work out what was needed and get on with it" (Senior manager, phase 3b) 
At the time when the role was created, the expectations for the role had not been thought out. As a result of this there was a deficiency in role sending from senior managers both to those divisional leaders who were responsible for selecting the change agent, and for the change agents themselves. This led to a lot of ambiguity in the role which the agents needed to resolve.

"None of us had done it before and we've never had any training in doing it before so we were basically making it up as we went along" (Change agent, phase 2)

"For the first few months we didn't really know what we were supposed to be doing" (Change agent, phase 2)

It became apparent as the role unfolded that the expectations of senior managers and divisional managers developed as they observed and evaluated the 'progress' which the individuals in the roles were making. During our interviews (phase 2 and beyond) we specifically probed mangers for evaluations of the change agents, encouraging them to articulate their role expectations which they had developed since our last visit and, as we later discovered, had failed to communicate to the change agents themselves. Due to this continued lack of role-sending we found that the expectations, which we were able to reveal, vastly differed between (a) senior managers who had created the role, (b) divisional managers who had recruited the role, and (c) the change agents themselves. In general, there was more alignment between the divisional managers and the change agents who had been working in closer proximity during this time.

"We wanted them to go out and become champions; but they haven't really done that. I envisaged them being very powerful, very influential; being a clinical 
champion; and making sure people were on board with it... convincing them it was the best way to do it" (Senior manager, phase 2).

"My role is to act as a facilitator to make sure that everything that needs to happen happens, to make sure we have the right paperwork, that the operating procedures are in order and that everything that needs to be thought of has been thought of" (Change agent, phase 2)

“[The change agent's] major aim is to make sure that everybody in my division knows exactly when we're moving, how they're going to get there, and what will happen when they do get there, and to make sure we do it safely. It's their job to make sure we have everything we need" (Divisional manager, phase 2)

Around the same time as our second phase of interviews, change agents became aware of the conflicting aspirations of these various groups and the full extent of the role ambiguity was exposed. We will describe the consequences of this in the final section.

\section{Role ambiguity and sensemaking}

Role ambiguity exists when there is uncertainty about what the role holder is supposed to do. This could be uncertainty about their membership to a particular role set (e.g. professional group or team) or it could be uncertainty about the purpose of the role, to what ends it is to serve (Katz and Kahn, 1978, Pearce and DeNisi, 1983). In this case there was uncertainty around both of these issues; change agents, situated between the project team and their former clinical groups: 
"The role was seen as being a bit of a pig in the middle, so being pulled by both hands [the project office and the divisions], as it were" (Divisional manager, phase $3 b)$.

“We work very closely with the project team now, but I don't feel like one of them, I have much more in common with my colleagues in [name of clinical department]" (Change agent, phase 2)

And also uncertainty about the purpose of the role and what it was hoped that they would achieve:

“We didn't really know what they wanted us to achieve... in the beginning we didn't really have an end goal in mind... it was just to move into the new hospital, we didn't get any advice about how to do it" (Change agent, phase 3b)

“What will success look like? Well, I don't know really, I guess I'll know it when I see it" (Change agent, phase 1)

Role ambiguity frustrates the human need for clarity and structure and if left unresolved may result in low job satisfaction; high tension; low self-confidence and lower performance effectiveness (see Katz and Kahn, 1978 for an overview). The uncertainty, created by the lack of role-sending, acted as a trigger for sensemaking by the change agents occupying the role.

Sensemaking occurs when an absence of clarity exists about a situation or when multiple possible explanations exist (Weick, 1995). When a disruption occurs in ongoing activity occurs (e.g. the reassignment to a new role), sensemaking is triggered to create 
meaning and to develop an interpretive schema to explain and guide their actions. In this case, the change agents engaged in sensemaking about the enactment of the role:

\begin{abstract}
"Once we got into the role, we didn't really know where to start, we had to come to an understanding about what our task involved" (Change agent, phase 1)
\end{abstract}

Sensemaking is a social act (Maitlis and Sonenshein, 2010, Weick et al., 2005, Maitlis, 2005) and therefore brought the group together to collectively 'make sense' of what they were experiencing. The group used dialogue and discussion to come up with a plausible understanding of what they thought they should be doing.

"We decided that we should all work together in one office so that we could discuss our activities and learn from each other... being all together helped us to find common ground in what we were doing" (Change agent, phase 1) "I had never worked with any of these people [other change agents] before, but we were all thrown together at the beginning and we discussed what we should do next" (Change agent, phase 2)

This sensemaking was based on the existing interpretive schema built from their previous experiences - or pre-existing logics (Maitlis and Sonenshein, 2010, Weick, 1988, Wicks, 2002). The agents formed a coherent group and together developed a sensemaking of the role based on their combined experiences.

We identified two main influencing factors on the change agent's sensemaking of the role: their combined views of the organisation, skills and experience; and contextual cues 
which they picked up from other organisational members. The initial role interpretation of the change agents reflected their previous divisional positions. Their view of the needs of the organisation focused on what they saw as the priorities at this level (i.e. answering operational questions, writing operational policies, coordinating different departments within the division):

"What's needed here is someone to do the nitty gritty, the paperwork, and to coordinate the operations... to check that we comply with the regulations, to order the equipment... it needs to be us because we know what the division needs" (Change agent, phase 3a)

This view contrasted with senior manager's perspectives which focused on wider strategic goals for the organisation and the change programme itself and who therefore saw engagement of front line staff as the priority. The change agents compared notes on the skills and experience which they had; attempting to find some common ground which would explain their selection and therefore represent an explanation of what was expected from them which made sense:

"So, me, [name of another change agent] and [name of another change agent] had written operating procedures before - quite extensively in my case, we assumed that was something which was relevant to this role, so that's why we did it" (Change agent, phase 3b)

"None of us really had any change management experience; we didn't know how to drive change... that was the job of [senior managers]" (Change agent, phase 2) 
They collectively analysed the plausibility of what they thought could be achieved given their existing skills and the role behaviour utilised these skills. The tasks they focused on were the ones they knew how to do.

The change agents also used contextual cues from other organisational members to guide their sensemaking. For example, when the project office allocated out their areas of responsibility (in terms of the wards and specialisms which they would cover) there was a significant mismatch between the divisional categorisation which existed within the organisational structure and the grouping which were provided by the project office (e.g. planned care wards were given to the same agent who was responsible for the emergency department despite their being in different divisions). This unexpected disruption from their initial understanding needed to be reinterpreted. The change agents interpreted this to mean that their role was not about translating the specific needs of their division, instead they should be seeking a standardised collection of activities and that they should work together to make decisions which suited everyone. This contrasted with the senior manager's expectations that they would tailor the operations to the needs of their individual divisions to make it easier for front line staff to adapt.

Similarly, the deployment of an organisation-wide communications strategy about the change project from senior management was interpreted as a cue that communicating this strategy was not part of their role:

"I didn't really need to pass on information to my user groups; they got it all in the newsletters and memos... I just answered any questions if they had any" (Change agent, phase 2) 
The sensemaking which emerged described the agents as providing an operational role, alleviating some of the administrative and functional tasks of the division leaders so that they could focus on the day to day running of the division, and to provide the technical details to the project team. The day-to-day aspects of the role were described as facilitating and coordinating, rather being vision-orientated or strategic. Everyday tasks included taking minutes, responding to queries and questions, arranging meetings, developing operational policy documents and move and migration plans. The actions of the change agents helped to solidify this sensemaking. They took on aspects of the change which noone else was doing and this gave their work meaning.

\section{Consequences}

Initially, in the enactment of the role, change agents focused on these operational tasks which they elucidated were their main priority from their sensemaking. This took up all of their time. Once the change agents became aware of the role expectations of senior managers, who wanted them to focus on internal stakeholder engagement and championing the new working practices, the agents attempted to respond to this. Role theory literature, which describes roles as flexible, would suggest that as new expectations were exerted from other linked roles, the individual would adjust their role behaviour to achieve a better fit between expectations and enactment (Katz and Kahn, 1978). However, we found that change agents were reluctant to relinquish their own sensemaking of the role. They still felt that the operational activities were much more important because no-one else was there to do them. This therefore led to an expansion of the role rather than an adjustment:

"Up until now we have been doing the operational side of the role, but now they want us to spend time engaging people as well" (Change agent, phase 2) 
Concerns about the enormity and complexity of the role were raised by a number of interviewees and in two of the divisions, circumstances led to more than one individual carrying out the role at various stages of the secondment and still the workload was described as unmanageable. More specifically, it seems that to some extent the number of tasks which agents could be involved in was infinite and they had difficulty prioritising the senior manager's expectations:

“They've become overwhelmed, absolutely overwhelmed, they can't keep their heads above water with the number of functions they are trying to perform" (Divisional manager, phase 3a)

One agent described how they still felt the need to prioritise operational issues (from their own sensemaking of the role) over the engagement issues (from the expectations of senior managers):

"It's been quite difficult because it's the operational side. And, whichever way you cut it, the operational side has always overtaken other things, it's been the priority for us from the beginning and we can't change that now... we are too far down the road" (Change agent, phase 2).

It became apparent that senior managers were relying very heavily on these change agents to do a majority of the engagement work of internal stakeholder and that they had no other strategies in place to do this. As a result, there was very little engagement from frontline staff in some divisions which made the post-transition period challenging. There was a long 
adjustment period and many staff struggled to understand why changes had been made the way that they had:

"I don't understand how we are supposed to work in this new environment, everything has changed" (nurse, phase 3a)

"It's been really difficult to adjust to the new work practices... it feels like we've been in survival mode ever since we moved in... I don't think they really thought through the implications of the single rooms... I don't understand why they did it this way; it makes no sense to me" (nurse, phase 3b)

In the later stages of our data collection and in their evaluations of the change, senior managers often complained about the effectiveness of the change agent role. They questioned whether the change agents had the 'correct' skills or attributes to perform the role and criticised the divisional leaders for selecting the wrong people:

“I perhaps would question whether they've got [the right personal skills] if I'm honest" (Senior manager, phase 3a)

"I don't know why they [the division leaders] picked the people that they did, none of them had any experience of bringing people on board with a project like this, they were all just good administrators... that wasn't what we needed" (Senior manager, phase 4)

In the aftermath, agents also felt much undervalued by the organisation in relation to their contribution: 
"I felt at the time, they're wasting me. Everything I've done over 18 months should be valued and should be appreciated and should be used" (Change agent, phase 3b)

\section{Discussion and conclusions}

The aim of this research was to improve our understanding of how change agents make sense of their role in organisational change management. This paper explored the creation of a formal change agent role in a large-scale hospital reconfiguration project and found that an absence of role-sending by senior managers led to uncertainty about the expected role behaviour. This ambiguity enabled us to study in detail the sensemaking process at work. Our data helps to explain how change agents collectively make sense of a role in their own way, drawing on their own experiences and views as well as cues from other organisational members. We also identified the organisational outcomes which resulted from this freedom in sensemaking. This study demonstrates that by leaving too much flexibility in the definition of the role, agents developed their own sensemaking which was subsequently very difficult to manipulate.

This paper highlights the importance of role sending in creating middle manager change agent roles. We have demonstrated the need to think through the purpose of change agent roles during healthcare change prior to their creation. We found that by not rolesending the role became too flexible, too under-defined and the sensemaking of the agents became different from that of senior managers. Instead of being guided by the expectations of those representing the strategic direction of the change, the agents favoured explanations which were more easily consolidated with their existing sensemaking based on their previous operational and division-based role. To them, the interpretation which derived from their existing logic was more plausible for them to enact. They took on activities which were not the responsibility of others and these actions validated their sensemaking. When confronted 
with a new situation or role, or a void in understanding created by change, uncertainty can create anxiety, leading to sensemaking. The objective of sensemaking is to reduce this anxiety by creating a plausible interpretation of the gaps, in this case, the new role (Weick, 1995, Weick et al., 2005). Our findings support role theory which suggests that it is the communication of role expectations which shape a role (Katz and Kahn, 1978), we highlight the added importance of this when a role is an entirely new creation rather than a replacement of an previous individual. In the role theory literature, it is often assumed that role expectations are readily available to the role holder (Mantere, 2008, Currie and Procter, 2005). Our study shows that this is not always the case and adds to our understanding by discussing what happens when they are not.

The lack of role-sending in this case study provided us with a good opportunity to see the sensemaking process at work and to understand the importance of (a) the social process of sensemaking, agents working together and seeking out discussion with peers in a similar position (b) previous interpretive schemes and logics which influenced the sensemaking which occurred, and (c) organisational cues in the form of actions and decisions of other organisational members, in influencing this process. We observed how agents used their combined skills and knowledge as a group to create a role description which they perceived adequately fulfilled the demands of the role and reduced the uncertainty created by the absence of a job description. The agents developed a shared mental model of the role which they believed they must perform (Mohammed and Dumville, 2001). Whilst research on shared mental models has been shown to improve team working and productivity, it can also result in a lack of adaptability if the way individuals carry out the role needs to change (Fiol, 2002, Baker et al., 2006). As we saw in this study, the role sending from senior managers, when it did eventually occur, was too late. Agents wouldn't let go of their already formed sensemaking. This could be due to their perspective seeming more plausible that the 
alternative one being imposed by senior managers which has been found to be a key factor in determining the preference for one interpretive frame over another (Weick, 1995, Weick et al., 2005, Naslund and Pemer, 2012, Weick, 2012). We saw here, that once the change progressed the role which the change agents had created became valuable. Their actions validated the need for an operational role. Their presence and actions ensured that others did not take on the operational responsibilities of the change which then led to cues which suggested that no-one else could take on these activities. They became responsible for the operational aspects because they started doing them (Weick, 1988). This then made it very difficult for them to stop doing them. It could also be a further illustration of the strategic ownership which change agents may take over determining their own role. Mantere (2008) argued role holders are not just passive recipients of role sending, but exhibit their own agency in determining the role enactment. This study helps us to understand the previously neglected power that change agents have in determining their own role. In our study the change agents took ownership over their position and performed it in a way which suited them.

Finally, we also highlight here the gap between theory on change management roles and the reality about their enactment in practice. The literature tells us about the many and complex possible roles which change agents can perform to enable or constrain organisational reconfiguration and there has been a large volume of research understanding which types of roles are needed at different times and situations (Parry, 2003, Greenhalgh et al., 2004, Chreim et al., 2012). However, in reality organisations do not always make this distinction and there is a tendency to try to utilise one individual to perform a variety of roles (Hendy and Barlow, 2012). It is thus important to distinguish between the differing expectations of different types of agent roles (e.g. champions, boundary spanners). In creating new roles, management firstly needs to have a realistic vision of the task and roles that their 
agents will perform, and secondly, to communicate these expectations to both those responsible for recruiting these roles and to the agents themselves.

The findings of this paper have implications for managers in healthcare organisations that work with, manage, select, train, or evaluate change agents. A key message to inform practice is that the role of the change agent needs to be thought out in advance of their selection and then processes of creating this role need to be aligned with this. Role creators must engage in role sending to guide and shape the role of change agents.

This study demonstrates the implications of senior management's failure to role-send and the consequences of allowing agents to sensemake their role without this guidance were apparent at both an immediate and longer term level. The difficulty of change management in healthcare has long been acknowledged in the literature, with lack of engagement from stakeholders cited as a key reason for limited success (McNulty and Ferlie, 2004). Here we found that the practical enactment of a role and the evaluations and expectations of this role rely on the accurate communication of role expectations. Where sensemaking of a role significantly varies this can impact on the fulfilment and evaluation of success for the organisation and the agents' sense of achievement.

\section{References}

BAKER, D., DAY, R. \& SALAS, E. 2006. Teamwork as an essential component of high reliability organizations. Health Services Research, 41.

BALL, B., KERIG, P. K. \& ROSENBLUTH, B. 2009. "Like a family but better because you can actually trust each other": the Expect Respect dating violence prevention program for atrisk youth. Health promotion practice, $10,45 \mathrm{~S}-58 \mathrm{~S}$.

BALOGUN, J. 2010. When organisations change: A middle management perspective on getting it right. In: (AIM), A. I. O. M. R. (ed.) Executive Briefing. London. 
BALOGUN, J. \& JOHNSON, G. 2004. Organizational Restructuring and Middle Manager Sensemaking. Academy of Management Journal, 47, 523-549.

BIRKEN, S. A., LEE, S. D. \& WEINER, B. J. 2012. Uncovering middle managers' role in healthcare innovation implementation. Implementation Science, 7, 28.

BOLTON, S. C. 2005. Making up managers: the case of NHS nurses. Work, employment and society, 19, 5-23.

CHREIM, S., WILLIAMS, B. E. \& COLLER, K. E. 2012. Radical change in healthcare organization: Mapping transition between templates, enabling factors, and implementation processes. Journal of Health Organization and Management, 26, 215- 236.

CORBIN, J. \& STRAUSS, A. S. 2008. Basics of Qualitative research: Techniques and procedures for developing grounded theory, Thousand Oaks, CA, Sage.

CURRIE, G. \& PROCTER, S. J. 2005. The antecedents of middle managers' strategic contribution: The case of a professional bureaucracy. Journal of Management Studies, 42, 1325-1356.

DOBERS, P. \& SODERHOLM, A. 2009. Understanding environmental and health care related organizational change. Journal of Organizational Change Management, 22, 480-493. DOBSON, S., FITZGERALD, L., FERLIE, E., GABBAY, G. \& LOCOCK, L. 2010. No magic targets! Changing clinical practice to become more evidence based. Healthcare Management Review, 35, 2-12.

DU GAY, P. 1996. Organizing identity: Entrepreneurial governance and public management'. In: HALL, S. \& DU GAY, P. (eds.) Questions of cultural identity. London: Sage. ECCLES, M., GRIMSHAW, J., WALKER, A., JOHNSTON, M. \& PITTS, N. 2005. Changing the behavior of healthcare professionals: the use of theory in promoting the uptake of research findings. Journal of Clinical Epidemiology, 58, 107-112. 
EVANS, J. M. \& BAKER, G. R. 2012. Shared mental models of integrated care: aligning multiple stakeholder perspectives. Journal of Health Organization and Management, 26, 713-736.

FERLIE, E., HARTLEY, J. \& MARTIN, S. 2003. Changing public service organizations: Current perspectives and future prospects. British Journal of Management, 14, s1-s14.

FIOL, M. 2002. Capitalizing on paradox: the role of language in transforming organizational identities. Organization Science, 13, 653-666.

GIOIA, D. A. \& CHITTIPEDDI, K. 1991. Sensemaking and sensegiving in strategic change initiation. Strategic Management Journal, 12, 433-448.

GIOIA, D. A., THOMAS, J. B., CLARK, S. M. \& CHITTIPEDDI, K. 1994. Symbolism and strategic change in academia: The dynamics of sensemaking and influence. Organization Science, 5, 363-383.

GREENHALGH, T., ROBERT, G., MACFARLANE, F., BATE, P. \& KYRIAKIDOU, O. 2004. Diffusion of Innovations in service organizations: Systematic review and recommendations. The Milbank Quarterly, 82, 581-629.

GREENHALGH, T., ROBERT, G., MACFARLANE, F., BATE, P., KYRIAKIDOU, O. \& PEACOCK, R. 2005. Storylines of research in diffusion of innovation: a metanarrative approach to systematic review. Social Science \& Medicine, 61, 417- 430.

HALES, C. 1999. Why do managers do what they do? Reconciling evidence and theory in accounts of managerial work. British Journal of Management, 10, 335-350.

HANNEY, S. R., GONZALEZ-BLOCK, M. A., BUXTON, M. J. \& KOGAN, M. 2003. The utilisation of health research in policy-making: concepts, examples and methods of assessment. Health research policy and systems, 1.

HENDY, J. \& BARLOW, J. 2012. The role of the organizational champion in achieving health system change. Social Science and Medicine, 74. 
HOWELL, J. M. \& HIGGINS, C. A. 1990. Champions of Technological Innovation. Administrative Science Quarterly, 35, 317-341.

HUMPHREYS, M., UCBASARAN, D. \& LOCKETT, A. 2012. Sensemaking and sensegiving stories of jazz leadership. Human Relations, 65, 41-62.

KATZ, D. \& KAHN, R. L. 1978. The Social Psychology of Organizations, New York, John Wiley \& Sons.

LOCOCK, L., DOPSON, S., CHAMBERS, D. \& GABBAY, J. 2001. Understanding the role of opinion leaders in improving clinical effectiveness. Social Science and Medicine, 53, 745757.

MACFARLANE, F., GREENHALGH, T., HUMPHREY, C., HUGHES, J., BUTLER, C. \& PAWSON, R. 2011. A new workforce in the making?: A case study of strategic human resource management in a whole-system change effort in healthcare. Journal of Health Organization and Management, 25, 55-72.

MAITLIS, S. 2005. The social processes of organizational sensemaking. Academy of Management Journal, 48, 21-49.

MAITLIS, S. \& SONENSHEIN, S. 2010. Sensemaking in crisis and change: Inspiriation and insight from Weick (1988). Journal of Management Studies, 47, 551-580.

MANTERE 2008. Role expectations and middle manager stratgic agency. Journal of Management Studies, 45, 294-316.

MCNULTY, T. \& FERLIE, E. 2002. Reengineering health careL the compoexities of organizational transformation, Oxford, Oxford University Press.

MCNULTY, T. \& FERLIE, E. 2004. Process transformation: Limitations to radical organizational change within public service organizations. Organization Studies, 25, 13891412. 
MOHAMMED, S. \& DUMVILLE, B. C. 2001. Team mental models in a team knowledge framework: expanding theory and measurement across disciplinary boundaries. Journal of Organizational Behavior., 22, 89-106.

NASLUND, L. 2009. "You can't improvise on nothin'": Attaining trust in the client consultant relationship. Client-consultant collaboration: Coping with complexity and change. Charlotte, NC: Information Age Publishing; US.

PARRY, J. 2003. Making sense of executive sensemaking: A phenomenological case study with methodological criticism. Journal of Health Organization and Management, 17, 240263.

PEARCE, J. A. \& DENISI, A. S. 1983. Attribution Theory and Strategic Decision Making: An Application to Coalition Formation. Academy of Management Journal, 26, 119- 128. PETTIGREW, A., FERLIE, E. \& MCKEE, L. 1992. Shaping strategic change - The case of the NHS in the 1980s. Public Money \& Management, 27-31.

ROULEAU, L. 2005. Micro-practices of strategic sensemaking and sensegiving: How middle managers interpret and sell change every day. Journal of Management Studies, 42, 14131441.

SCHON, D. A. 1963. Champions for Radical New Inventions. Harvard Business Review, 41, $77-86$.

SNOW, T. 2008. Planning the future of ward design. Nursing Standard, 23, 12-13.

SOO, S., BERTA, W. \& BAKER, R. 2009. Role of champions in the implementation of patient safety practice change. Healthcare Quarterly, 12, 123-128.

STARBUCK, W. H. \& MILLIKEN, F. J. 1988. Executives perceptual filters: What they notice and how they make sense. In: HAMBRICK, D. (ed.) The executive effect: Concepts and methods for studying top managers. Greenwich, CT: JAI Press. 
TUCKER, D. A., HENDY, J. \& BARLOW, J. Sensemaking and social accounts in middle managers. Academy of Management Annual Meeting, 2012 Boston, MA. Academy of Management.

TURNER, R. 1978. The role and the person. American Journal of Sociology, 84, 1-23. WEICK, K. 1995. Sensemaking in Organizations, Thousand Oaks, Sage. WEICK, K., SUTCLIFFE, K. M. \& OBSTFELD, D. 2005. Organizing and the process of sensemaking. Organization Science, 16, 409-421.

WEICK, K. E. 1988. Enacted sensemaking in crisis situations. Journal of Management Studies, 25, 305-17.

WICKS, D. 2002. Institutionalized mindsets of invulnerability: Differentiated institutional fields and the antecedents of organizational crisis. Organization Studies, 22.

WOOLDRIDGE, B., SCHMID, T. \& FLOYD, S. W. 2008. The middle management perspective on strategy process: Contributions, synthesis, and future research. Journal of Management, 34, 1190-1221. 
Table 1 - Data Collection

\begin{tabular}{|c|c|c|c|c|c|c|c|c|}
\hline Data Source & $\begin{array}{l}\text { Phase } 1 \\
\text { (January- } \\
\text { September 2010) }\end{array}$ & $\begin{array}{l}\text { Phase } 2 \\
\text { (October 2010- } \\
\text { January 2011) }\end{array}$ & $\begin{array}{c}\text { Transition } \\
1 \\
\text { (January }\end{array}$ & $\begin{array}{l}\text { Phase 3a } \\
\text { (February- } \\
\text { July 2011) }\end{array}$ & $\begin{array}{c}\text { Transition } \\
2 \\
\text { (September }\end{array}$ & $\begin{array}{l}\text { Phase 3b } \\
\text { (August 2011- } \\
\text { January } \\
\text { 2012) }\end{array}$ & $\begin{array}{c}\text { Phase } 4 \\
\text { (February - } \\
\text { December 2012) }\end{array}$ & TOTAL \\
\hline Formal Interviews: & (Jan-April) & $(O c t-D e c)$ & 2011) & (March-April) & 2011) & (Dec-Jan) & (Oct-Dec) & \\
\hline Executive Directors & 3 & 6 & & 4 & & 1 & 2 & 16 \\
\hline Other Trust Management & 4 & 3 & & - & & 2 & 2 & 11 \\
\hline Project Management Office & 7 & 4 & & 1 & & 2 & 1 & 15 \\
\hline Divisional Directors & - & 4 & & 4 & & 5 & 2 & 15 \\
\hline Change Management Agents & 4 & 5 & & 2 & & 4 & - & 15 \\
\hline Lower management/Frontline staff & - & - & & 3 & & 7 & - & 10 \\
\hline Total & 18 & 22 & & 14 & & 21 & 7 & 82 \\
\hline \multicolumn{9}{|l|}{ Observations (hrs.): } \\
\hline Hospital tours & 2 & 2 & & 1 & & 1 & - & 6 \\
\hline Informal observation (public areas) & - & 17 & & 4 & & 15 & 9 & 45 \\
\hline Total & 2 & 19 & & 5 & & 16 & 9 & 51 \\
\hline \multicolumn{9}{|l|}{ Documents: } \\
\hline Internal documents & 6 & 8 & & 2 & & 2 & - & 18 \\
\hline Government/National documents & 1 & - & & - & & - & 3 & 4 \\
\hline Media & 20 & 2 & & 30 & & 22 & 7 & 81 \\
\hline External parties (e.g. campaigns) & 1 & - & & - & & - & - & 1 \\
\hline Impressions/case notes & 1 & 3 & & 2 & & 4 & 2 & 12 \\
\hline Total & 29 & 13 & & 34 & & 28 & 12 & 116 \\
\hline
\end{tabular}

